\title{
The Postpartum Period as a Point of Prevention for Opioid Misuse: A Commentary
}

\author{
Yukiko Washio', Jessica Kelley Morgan², Gail Herrine³, Steven K. Walther ${ }^{4}$ \\ ${ }^{1}$ Substance Use, Gender, and Applied Research, RTI International, Research Triangle Park, NC, USA \\ ${ }^{2}$ Behavioral Health Research Division, RTI International, Research Triangle Park, NC, USA \\ ${ }^{3}$ Department of Obstetrics, Gynecology and Reproductive Sciences, Temple University Lewis Katz School of Medicine, \\ Philadelphia, PA, USA \\ ${ }^{4}$ Continuous Precision Medicine, Research Triangle Park, NC, USA \\ Email: ywashio@rti.org
}

How to cite this paper: Washio, Y., Morgan, J. K., Herrine, G., \& Walther, S. K. (2020). The Postpartum Period as a Point of Prevention for Opioid Misuse: A Commentary. Psychology, 11, 1179-1184. https://doi.org/10.4236/psych.2020.118078

Received: April 16, 2020

Accepted: August 21, 2020

Published: August 24, 2020

Copyright $\odot 2020$ by author(s) and Scientific Research Publishing Inc. This work is licensed under the Creative Commons Attribution International License (CC BY 4.0).

http://creativecommons.org/licenses/by/4.0/

(c) (i) Open Access

\begin{abstract}
The nationwide increase in opioid use has led to an epidemic in the United States, resulting in an increase of opioid-related overdose deaths and opioid analgesic prescriptions over the last two decades. The risk of long-term opioid use post-surgery increases when patients are treated with opioid analgesics compared to their counterparts. Guidelines state that opioid analgesics are not always necessary and should be prescribed for the lowest effective dose only as long as pain is expected to be severe; however, over-prescription is common with general populations showing that half the amount of prescribed opioids do not get used by patients. Obstetric delivery is one of the most common procedures experienced among women who are pregnant. Recent evidence shows that many variations exist in opioid prescription rates during postpartum across states, ranging from $7 \%$ to $53 \%$ with differences in dosages for greater than 280 morphine milligram equivalents following uncomplicated vaginal delivery, indicating opportunities to develop guidelines on postpartum opioid use but also to improve prescription safety as well as to prevent an unnecessary increase in prescription opioid misuse among postpartum women. Telemedicine for monitoring substance use is increasingly common for substance use treatment programs and electronic technology is also being explored to screen and deliver brief interventions to treat substance use, drinking, and smoking in maternal populations. Given the myriad psychosocial risk factors associated with the postpartum period and the introduction of opioids to many opiate-naïve patients during this time, obstetric delivery may be an optimal time for upstream opioid misuse prevention using mobile technology. The objective of this commentary is to describe the prevalence of maternal opioid use and importance of addressing it with a study to prevent development of maternal opioid misuse.
\end{abstract}




\section{Keywords}

Opioid Misuse, Postpartum, Prevention, Mobile Technology, Addiction

\section{Introduction}

The nationwide increase in opioid use has led to an epidemic in the United States (Martins et al., 2017), resulting in an increase of opioid-related overdose deaths and opioid analgesic prescriptions over the last two decades (Dart et al., 2015; Paulozzi, Jones, Mack, \& Rudd, 2011). The risk of long-term opioid use post-surgery increases when patients are treated with opioid analgesics compared to their counterparts (Alam et al., 2012; Bateman et al., 2016; Deyo et al., 2017; Shah, Hayes, \& Martin, 2017). Guidelines state that opioid analgesics are not always necessary and, when used, they should be prescribed for the lowest effective dose only as long as pain is expected to be severe (Javaher \& Mai, 2015); however, over-prescription is common with general populations showing that half the amount of prescribed opioids do not get used by patients (Bates, Laciak, Southwick, \& Bishoff, 2011; Bicket, Long, Pronovost, Alexander, \& Wu, 2017).

Obstetric delivery is one of the most common procedures experienced among women who are pregnant (Martin, Hamilton, Osterman, Driscoll, \& Drake, 2018). Recent evidence shows that many variations exist in opioid prescription rates during postpartum across states, ranging from $7 \%$ to $53 \%$ with differences in dosages for greater than 280 morphine milligram equivalents following uncomplicated vaginal delivery (Becker, Gibbins, Perrone, \& Maughan, 2018). Since 2002, prescription opioid use and misuse have significantly increased among women who are pregnant and non-pregnant, showing over $31 \%$ increase in past-month heroin use among women of childbearing age (Substance Abuse and Mental Health Services Administration, 2015). Although women treated for opioid use disorders with opioid agonist therapy show better maternal and infant outcomes, evidence-based criteria for treating women with opioid use disorders is largely absent (Klaman et al., 2017). Women with opioid use disorder have multiple co-occurring substance use and mental health issues, including co-use of other substances, tobacco use, psychiatric disorders, family and social issues, and sexual health complications (Hand, Short, \& Abatemarco, 2017). These indicate opportunities to develop guidelines on postpartum opioid use but also to improve prescription safety as well as to prevent an unnecessary increase in prescription opioid misuse among postpartum women (Becker et al., 2018).

\section{Description of the Recent Pilot Study on Pain Medication Use}

A recent study in the United States (Morgan, Walther, \& Lane, 2019) used a mobile application technology to track pain and usage of opiates and non-steroidal anti-inflammatory medications (NSAID) that manage pain. The mobile applica- 
tion uses elements of gamification to encourage patients to delay medications when appropriate and to decrease dosages as able. Patients are asked to rate their pain level and, if appropriate, encouraged to delay opioid medication intake or use an alternative (e.g., an NSAID or acetaminophen), followed by earning points.

Univariate analyses were conducted to examine the distribution of participant responses related to acceptability, namely ease of use and logistical feasibility for both patients and clinicians. The feasibility of the mobile application was examined by group-level rates of opioid use and habit-forming behaviors. Preliminary results included time to delay of next opioid use, time to reduction of opioid use, overall consumption of prescribed opioids, and plasma concentration and tolerance levels with regard to opioids. A total of eight participants underwent outpatient surgeries have tried using the application post-surgery with five male and three female patients. Seven of them began delaying the next opioid dose and took less than the recommended dosage within 24 hours post-operation. They took less than half the prescribed opioids and consumed less than two-third of the recommended opioids to manage their pain, decreasing their plasma concentration and reducing the risk of habit-forming behaviors. A total of 180 oxycodone pills were prescribed across the seven patients with only 39 pills (21\%) having been taken leaving 141 pills unused. Future research efforts should include a randomized controlled trial to determine if and how much of these behaviors can be attributed to application usage.

\section{Comparisons with Other Technologies}

Mobile technology has been explored in treating alcohol use among obstetric populations (Washio, Frederick, Archibald, Bertram, \& Crowe, 2017). Alcohol use can be detected by breathalyzer, which has been available for mobile use connected to Wifi for transmitting GPS, facial recognition results, and blood alcohol concentrations (BAC) (Skipper et al., 2014). The small community project described in Washio et al. (2017) was implemented by community stakeholders (schools and the state government) in the United States to remotely monitor prenatal alcohol use via mobile breathalyzer and provide weekly financial incentives for alcohol abstinence. The project was in collaboration with social services providing case management for women who are pregnant and use alcohol. Four participants showed over $90 \%$ monitoring compliance, and none provided alcohol-positive breath samples (Washio et al., 2017).

Computerized behavioral interventions are more common to treat maternal substance, alcohol, and tobacco use, compared to mobile technology use (Ondersma et al., 2012; Ondersma et al., 2015, 2018). Computerized behavioral interventions are usually provided in a brief form such as a single session. The computer program has a three-dimensional, mobile, emotionally expressive animated narrator reading materials regarding pros and cons of substance use and related issues, as well as query in interest in changing substance use with an optional goal setting. The program is individually tailored so that it navigates the 
participants according to whether they are ready to abstain and set up a goal to achieve.

\section{Future Directions}

Telemedicine for monitoring substance use is increasingly common for substance use treatment programs with opioid agonist therapy to reach populations in rural settings or those with transportation barriers (Eibl et al., 2017). Electronic technology is also being explored to screen and deliver brief interventions to treat substance use, drinking, and smoking in maternal populations (Ondersma et al., 2012; Ondersma et al., 2015, 2018; Washio et al., 2017). As described in the study above (Morgan et al., 2019), simply tracking their pain level and getting encouragement and motivation to delay pain medication intake might also help immediate postpartum women to prevent an unnecessary increase in prescription opioid misuse post-delivery. Given the myriad psychosocial risk factors associated with the postpartum period and the introduction of opioids to many opiate-naïve patients during this time, obstetric delivery may be an optimal time for upstream opioid misuse prevention, and use of mobile technology may increase user and provider engagement to properly manage pain medication.

\section{Conflicts of Interest}

The authors declare no conflicts of interest regarding the publication of this paper.

\section{References}

Alam, A., Gomes, T., Zheng, H., Mamdani, M. M., Juurlink, D. N., \& Bell, C. M. (2012). Long-Term Analgesic Use after Low-Risk Surgery: A Retrospective Cohort Study. Archives of Internal Medicine, 172, 425-430. https://doi.org/10.1001/archinternmed.2011.1827

Bateman, B. T., Franklin, J. M., Bykov, K., Avorn, J., Shrank, W. H., Brennan, T. A. et al. (2016). Persistent Opioid Use Following Cesarean Delivery: Patterns and Predictors among Opioid-Naïve Women. American Journal of Obstetrics and Gynecology, 215, 353.e1-353.e18. https://doi.org/10.1016/j.ajog.2016.03.016

Bates, C., Laciak, R., Southwick, A., \& Bishoff, J. (2011). Overprescription of Postoperative Narcotics: A Look at Postoperative Pain Medication Delivery, Consumption and Disposal in Urological Practice. Journal of Urology, 185, 551-555. https://doi.org/10.1016/j.juro.2010.09.088

Becker, N. V., Gibbins, K. J., Perrone, J., \& Maughan, B. C. (2018). Geographic Variation in Postpartum Prescription Opioid Use: Opportunities to Improve Maternal Safety. Drug and Alcohol Dependence, 188, 288-294. https://doi.org/10.1016/j.drugalcdep.2018.04.011

Bicket, M. C., Long, J. J., Pronovost, P. J., Alexander, G. C., \& Wu, C. L. (2017). Prescription Opioid Analgesics Commonly Unused after Surgery: A Systematic Review. JAMA Surgery, 152, 1066-1071. https://doi.org/10.1001/jamasurg.2017.0831

Dart, R. C., Surratt, H. L., Cicero, T. J., Parrino, M. W., Severtson, S. G., Buch- 
er-Bartelson, B., \& Green, J. L. (2015). Trends in Opioid Analgesic Abuse and Mortality in the United States. New England Journal of Medicine, 372, 241-248.

https://doi.org/10.1056/NEJMsa1406143

Deyo, R. A., Hallvik, S. E., Hildebran, C., Marino, M., Dexter, E., Irvine, J. M. et al. (2017). Association between Initial Opioid Prescribing Patterns and Subsequent Long-Term Use among Opioid-Naïve Patients: A Statewide Retrospective Cohort Study. Journal of General Internal Medicine, 32, 21-27. https://doi.org/10.1007/s11606-016-3810-3

Eibl, J. K., Gauthier, G., Pellegrini, D., Daiter, J., Varenbut, M., Hogenbirk, J. C., \& Marsh, D. C. (2017). The Effectiveness of Telemedicine-Delivered Opioid Agonist Therapy in a Supervised Clinical Setting. Drug and Alcohol Dependence, 176, 133-138. https://doi.org/10.1016/j.drugalcdep.2017.01.048

Hand, D. J., Short, V. L., \& Abatemarco, D. J. (2017). Treatments for Opioid Use Disorder among Pregnant and Reproductive-Aged Women. Fertility and Sterility, 108, 222-227. https://doi.org/10.1016/j.fertnstert.2017.06.011

Javaher, S., \& Mai, J. (2015). Interagency Guideline on Prescribing Opioids for Pain Written for Clinicians who Care for People with Pain. http://www.agencymeddirectors.wa.gov/

Klaman, S. L., Isaacs, K., Leopold, A., Perpich, J., Hayashi, S., Vender, J. et al. (2017). Treating Women Who Are Pregnant and Parenting for Opioid Use Disorder and the Concurrent Care of Their Infants and Children: Literature Review to Support National Guidance. Journal of Addiction Medicine, 11, 178-190. https://doi.org/10.1097/ADM.0000000000000308

Martin, J. A., Hamilton, B. E., Osterman, M. J. K., Driscoll, A. K., \& Drake, P. (2018). Births: Final Data for 2016. National Vital Statistics Reports, 67, 1-55. http://www.ncbi.nlm.nih.gov/pubmed/29775434

Martins, S. S., Sarvet, A., Santaella-Tenorio, J., Saha, T., Grant, B. F., \& Hasin, D. S. (2017). Changes in US Lifetime Heroin Use and Heroin Use Disorder. JAMA Psychiatry, 74, 445-455. https://doi.org/10.1001/jamapsychiatry.2017.0113

Morgan, J. K., Walther, S. K., \& Lane, M. E. (2019). Evaluation of a Mobile Application to Decrease Opioid Misuse and Habit-Forming Behaviors Following Prescription: Preliminary Results and Future Directions. Psychology, 10, 2019-2025.

https://doi.org/10.4236/psych.2019.1015129

Ondersma, S. J., Beatty, J. R., Svikis, D. S., Strickler, R. C., Tzilos, G. K., Chang, G. et al. (2015). Computer-Delivered Screening and Brief Intervention for Alcohol Use in Pregnancy: A Pilot Randomized Trial. Alcoholism: Clinical and Experimental Research, 39, 1219-1226. https://doi.org/10.1111/acer.12747

Ondersma, S. J., Svikis, D. S., Lam, P. K., Connors-Burge, V. S., Ledgerwood, D. M., \& Hopper, J. A. (2012). A Randomized Trial of Computer-Delivered Brief Intervention and Low-Intensity Contingency Management for Smoking During Pregnancy. Nicotine \& Tobacco Research, 14, 351-360. https://doi.org/10.1093/ntr/ntr221

Ondersma, S. J., Svikis, D. S., Thacker, C., Resnicow, K., Beatty, J. R., Janisse, J., \& Puder, K. (2018). Computer-Delivered Indirect Screening and Brief Intervention for Drug Use in the Perinatal Period: A Randomized Trial. Drug and Alcohol Dependence, 185, 271-277. https://doi.org/10.1016/j.drugalcdep.2017.12.022

Paulozzi, L. J., Jones, C. M., Mack, K. A., \& Rudd, R. A. (2011). Vital Signs: Overdoses of Prescription Opioid Pain Relievers-United States, 1999-2008. Morbidity and Mortality Weekly Report, 60, 1487-1492.

Shah, A., Hayes, C. J., \& Martin, B. C. (2017). Characteristics of Initial Prescription Episodes and Likelihood of Long-Term Opioid Use-United States, 2006-2015. Morbidity 
and Mortality Weekly Report, 66, 265-269. https://doi.org/10.15585/mmwr.mm6610a1

Skipper, G. E., Thon, N., DuPont, R. L., Campbell, M. D., Weinmann, W., \& Wurst, F. M. (2014). Cellular Photo Digital Breathalyzer for Monitoring Alcohol Use: A Pilot Study. European Addiction Research, 20, 137-142. https://doi.org/10.1159/000355834

Substance Abuse and Mental Health Services Administration (2015). Behavioral Health Trends in the United States: Results from the 2014 National Survey on Drug Use and Health. Center for Behavioral Health Statistics and Quality.

Washio, Y., Frederick, J., Archibald, A., Bertram, N., \& Crowe, J. A. (2017). Community-I Nitiated Pilot Program "My Baby's Breath" to Reduce Prenatal Alcohol Use. Delaware Medical Journal, 89, 46-51. http://www.ncbi.nlm.nih.gov/pubmed/29693817 